\title{
APPLICATION OF MULTI-CRITERIA APPROACH FOR SUSTAINABILITY ASSESSMENT OF MANUFACTURING PROCESSES
}

\author{
Aldona Kluczek \\ Warsaw University of Technology, Faculty of Production Engineering, Poland \\ Corresponding author: \\ Aldona Kluczek \\ Warsaw University of Technology \\ Faculty of Production Engineering \\ Institute of Organization of Production Systems \\ Narbutta 86, 02-524 Warszawa, Poland \\ phone: $(+48) 22$ 234-8133 \\ e-mail:a.kluczek@wip.pw.edu.pl
}

Received: 21 April 2016

Accepted: 1 September 2016

\begin{abstract}
The paper is to present a multi-criteria approach for sustainability assessment of manufacturing processes, which can be applied to carry out the sustainability assessment of manufacturing processes requiring less detailed data, time, and expert knowledge, but still providing a company-level analysis. The analytical hierarchy process method is used to determine ranking of simple and relevant activity areas for manufacturing processes in terms of sustainability objectives. Analytical technique is also employed to assess the degree of sustainability in manufacturing due to limited information which appear to be a characteristic of the case study presented. One goal of sustainability characterization methodology is to improve the manufacturing sustainability performance. Similar to the baseline scenario, sustainability reevaluation for sustainability improvement is also applied and discuses performance profile at the process level. This approach seems particularly useful when comparing different processes. It makes applicable for various industries and might be a challenge to derive priorities for systematic improvement. The applicability and usability of the proposed assessment method was verified by the case study in company producing heating devices.
\end{abstract}

KEYWORDS

multi-criteria decision analysis, analytical hierarchy process, sustainability assessment, manufacturing.

\section{Introduction}

The increasing concern about sustainability initiates the necessity of assessment manufacturing activities $[1,2]$. The Science and Technology Policy Institute white papers also stressed the "need for accessible and affordable measurement systems and analytical tools for assessing [...] across the production process" [3]. Hence, it has become mandatory to assess the degree of sustainability in manufacturing in order to set plans on how to improve it $[4,5]$. Sustainability drive paraphrased as "people, planet, profit" $[6]$ or "triple bottom line" $[7,8]$ is measured to cover its totality. The first, people, concerns corporate so- cial responsibility. The second, planet, refers to sustainable environmental practices. The third, profit, is the economic value created by the organization. The three together involves the use of available resources and the generation of new resources, quality initiatives, environmental costing.

Considerations on the three interlinked sustainability components form the basis for measuring and assessing the performance of enterprises, thus sustainability production processes. On that point, decision-support methods are needed, not only to improve environmental aspects of manufacturing, but also to ensure long-term productivity and social wellbeing [8]. Following the concept, it also requires a de- 
velopment of metrics for sustainability by developing quantitative or qualitative indicators [9-12]. It, in turn, needs to identify interactions for each manufacturing process.

This strong promotion of sustainable issues in industry in recent years forces enterprises from heating sectors to assess their performance from these three perspectives. Boiler production comprises many processes each of which has its own technical specification. An attempt to assess sustainability in manufacturing processes will require consideration of the activity areas between their differing sustainable objectives using decision-making methods. In this case, defining sustainable assessment methods for manufacturing consists of decision-making problems with different components [13]. It includes, on the first hand, technical aspects, costs, environmental and social aspects, on the second hand, components for manufacturing processes.

Although in recent years, various methods and approaches have been developed for sustainability assessment of production processes at the national level or for cross-country comparisons, but the issue of developing a combined method as multi-criteria at the process level is not properly addressed. From the literature, although generic methods to evaluate sustainability performance are not available, manufacturing processes sustainability performance evaluation models are under development [14]. To assess and improve sustainability performance in manufacturing, it is needed to develop straightforward, ease of use methods, which can be applied in diverse manufacturing scenarios.

Considering this research gap, there is a lack of holistic focus on development of criteria and sustainability objectives (technical, environment, economic and social) for different sustainable manufacturing assessment from SME. Additionally, sustainability assessment of manufacturing was not yet considered on the process level and applicable for use in a proactive company in its continuous efforts to improve sustainability performance. Time consuming assessment due to the complexity and amount of data required is usually quite limited. Besides the technical sustainability is a novel objective and a contributor to the sustainability assessment of manufacturing.

In this sense, the author focuses on the concept of a new approach in the sustainability objectives and AHP within the framework of MCDA. It allows the development of an approach which can be applied by the company to carry out an overall sustainability assessment requiring less detailed data, time, and expert knowledge, but still providing a company-level analysis. The author does this by exploring the possi- bilities of applying modified version of the AHP [15, $16]$ in a simplified manner for ranking activity areas for manufacturing processes.

The present study developed a composite multicriteria approach for sustainability assessment of manufacturing processes based on an enterprise producing heating devices. This approach allows the company considered to incorporate sustainability objectives - social, environmental, economic, and technical - into production processes simultaneously. In order to unify assessment method, the sustainability assessment will be based on mostly qualitative data taken from on-site visits carried out.

\section{Rationale for sustainability assessment of manufacturing processes}

A rationale for sustainable assessment in production is treated as a core requirement in sustainabilityrelated research, where both qualitative and quantitative information can be used [17]. Many industrial enterprises should rethink how to produce products to improve profits and competitiveness and to reduce environmental impacts at the same time. To achieve sustainable manufacturing, there are needed major changes in manufacturing defined by various authors [18, 19]. Manufacturing decision makers consider several aspects such as technology selection, supplier selection, production planning and control, inventory management, workforce management, quality management, and process prioritization must be considered [20]. The state-of-the-art study has shown that significant effort is spent in developing of diverse approaches for the assessment and improvement of sustainability [20], at different levels of abstraction, namely manufacturing process, plant floor, enterprise [14].

The most significant challenge for implementing sustainable manufacturing at the process level is to develop quick and convenient sustainability assessment approach without compromising significantly on comprehensiveness involves the use of the analytic hierarchy process (AHP) to prioritize sustainability manufacturing activity areas based on the limited data for a particular manufacturing process.

\section{Literature review}

Literature has been reviewed from the perspectives of multi-criteria decision analysis (MCDA) and an attempt of AHP application in manufacturing sustainability assessment. Numerous examples of applications of MCDA methods have been repor- 
ted [21-23]. MCDA approach methodologies aim to determine overall preferences among alternative options according to the different criteria being difficult while comparing with one another [24]. It allows the use of such heterogeneous criteria like costs and benefits of the project, environmental quality in physical and qualitative terms, and social impact in non-monetary terms. The measurements of indicators do not need to be in the monetary terms, but are often based on the qualitative analysis (through scoring, ranking and weighting). Desired values of the certain criteria are estimated, difficult to measure and subjective, which are stated as "good" or "much better" [25]. This means that MCDA tools can be customized to incorporate value judgments of individual or multiple decisions makers [26]. One of the greatest weaknesses of MCDA is the subjectivity of the weighting step that is needed to value the different criteria. Although the methods described above often seem to lack precision, they can provide an estimate of an enterprise's sustainability performance. The selection of a certain MCDA method has to be based on an appropriate knowledge of the basics of the approach and the evaluation to be performed as well. This implies the recognition that some aspects can be covered only by certain methods [17].

"Some multi-criteria methods, in particular, the AHP, serve to further entrench the problem" [27] or "problematics" [28]. AHP determines the criteria weights indirectly based on scores of relative importance for each in pair-wise comparison. The main concern of AHP is dealing with inconsistencies arising with the judgment and improving this judgment. This intricacy has been dealt with to ensure that the judgments are consistent enough to give weights for multi-attribute activity areas and to "establish priorities". This method has been employed widely in decision-making problems involving multiple criteria in systems of many levels [29-33].

Hence, due to its mathematical simplicity and flexibility, AHP seems to be well-suited to manufacturing processes assessment towards sustainable development by using a pair-wise comparison technique (judgments) between criteria with regards to the each criterion. Due to expert's statements are uncertain in their nature, human thoughts are fuzzy and the problem being analyzed is complex, then it is proposed to apply successfully fuzzy logic to help handle imprecision in multi-criteria decision making processes [34]. Hence, an effective approach in the decision-making area to evaluate and select businesses, in the context of collaborative networked organizations, was presented based on a dynamic multi- criteria decision model (DMCDM) [35]. Further, the dynamic DMCDM model was extended to consider a time frame in terms of both past behavior and future information [36]. The recent research in the decision-making area provided some extensions against a dynamic MCDM, regarding the integration of several distinct technologies, smart objects for local and remote data collection and processing directly from manufacturing resources or managers [37].

Although MCDA methodologies appear to be promising for dealing with complex decision-making, there has been a verified limited information in the literature about their use in the industrial plants producing central heating boilers.

Other methods developed to perform sustainability assessment studies are focusing on covering only a certain object of sustainability (i.e. life cycle assessment), while MCDA allows to cover more sustainability pillars [17].

Life cycle assessment (LCA) designed for measuring and assessing environmental and economic effect along with social life cycle assessment model have proposed by [38] is difficult due to complexity of processes and lack of parameters as well as values describing characteristics of criteria activity areas.

The rationale for not developing parameters and values was based on partially quantitative and mostly qualitative information. The paper does not introduce real "improvement ratios" [39] between existing and new technology in specific heating industry. Serious estimates of improvement ratios require relatively "deep knowledge" of the production process based on cleaner production audits [40], comparison with best available technologies [19] and comparative life cycle assessment [41, 42].

The assessment methods used depend on the character of the project or scientific research as well as the information available. When selecting methods, it should consider methods which allow to aggregate and summarize the data into smaller sets with least loss of information. One of the main requisites of sustainability assessment is that every indicator is provided by standard-based measurement methods, in a tightly integrated manner with business operation [43]. As such, the manufacturing assessment might be done in multiple passes with analytical tools [44].

Some selection approaches have been developed in the literature to assess sustainability in companies $[44,45]$. Moreover, additional assessment methods using other analytical techniques would still be necessary. 


\section{Materials and methods}

The present study designed an information model for assessing the manufacturing sustainability performance for a company producing heating devices. In this paper, the AHP method and 5-point scale was used to serve the purpose of the study.

Manufacturing process of boilers involves multiple sub-processes represented by various kinds of performance data. The data provided by the company is incomplete and not necessarily sufficient. What is more, the complexity of manufacturing processes may make sustainability assessment impossible according to the various parameters. From the other hand, the sustainability assessment procedure must also be sufficiently generic and broad to cover as much of the detail as possible that would be cov- ered in a comprehensive procedure. Various in operations manufacturing technologies need to be based upon procedure for simplifying sustainability assessment in order to easy compare with baseline scenario. Hence, there is need for:

- applying a feasible, quick approach for the assessment and improvement of sustainability on the process level against the four sustainability objectives,

- unifying manufacturing processes in terms of categories of each manufacturing process. These criteria, called "activity areas", are designated to different processes of boiler production. The analysis and assessment were framed in terms of technological changes (replacement the existing machines by more advanced ones) in manufacturing processes for the considered company as shown in Table 1.

Table 1

Potential benefits of implementing selected improvement technologies in the manufacturing processes.

\begin{tabular}{|c|c|c|c|}
\hline No. of process & $\begin{array}{c}\text { Proposed technologies, } \\
\text { changes in existing technology }\end{array}$ & Potential benefits & Savings/loss [US\$; \%] \\
\hline M1 & $\begin{array}{l}\text { - Replacement plasma cutter with } \\
\text { laser cutter. } \\
\text { - Workplaces converted to laser cut- } \\
\text { ting will be equipped with filtered } \\
\text { ventilation system. }\end{array}$ & $\begin{array}{l}\text { Converting from plasma to laser cut- } \\
\text { ting reduced: } \\
\text { - dust emissions from } 7.2 \mathrm{~kg} / \text { year to } \\
3.6 \mathrm{~kg} / \text { year, } \\
\text { - material waste - from about } 12,000 \\
\mathrm{~kg} / \text { year down to about } 9,000 \\
\text { kg/year, } \\
\text { - annual reduction in electricity. }\end{array}$ & $\begin{array}{c}{[2 ; 50]} \\
{[2370 ; 25]} \\
{[6479 ; 56]}\end{array}$ \\
\hline M2 & $\begin{array}{l}\text { - The use of push - pull welding venti- } \\
\text { lation system with a high efficiency } \\
\text { dust filter of } 99 \% \text {. } \\
\text { - The use of general ventilation with } \\
\text { central vacuum and filtering sys- } \\
\text { tems equipped with cartridge filter } \\
\text { units to reduce welding fumes and } \\
\text { gases. }\end{array}$ & $\begin{array}{l}\text { The installation of ventilation systems } \\
\text { reduced: } \\
\text { - dust from the welding process up } 30 \\
\text { kg/year, } \\
\text { - electricity and increased in electrici- } \\
\text { ty consumed by the ventilations sys- } \\
\text { tems is } 192,240 \mathrm{MJ} / \text { year. }\end{array}$ & $\begin{array}{c}{[13.2 ; 5]} \\
{[83.6 ; 16]} \\
{[-10,146 ; 147]}\end{array}$ \\
\hline M3 & $\begin{array}{l}\text { - Replacing sand blasting equipment } \\
\text { and solvents degreasers with shot- } \\
\text { blasting booth with a closed abra- } \\
\text { sive circuit system, equipped with } \\
\text { integral filter system to reduce dust. }\end{array}$ & $\begin{array}{l}\text { The new shot blasting installations } \\
\text { eliminated: } \\
\text { - the need for } 258 \text { tons of sand by } \\
\text { replacing it with steel shot for the } \\
\text { cleaning abrasive ( } 4.2 \text { tons), } \\
\text { - using steel shot blast instead of sand } \\
\text { as the abrasive reduced dust emit- } \\
\text { ted by the cleaning process by up to } \\
8.3 \mathrm{~kg} / \text { year. }\end{array}$ & $\begin{array}{c}{[41,323 ; 98]} \\
{[143 ; 98]}\end{array}$ \\
\hline M4 & $\begin{array}{l}\text { - Installation of the paint spraying } \\
\text { and drying cabins with air recir- } \\
\text { culation loop using hydrodynamic } \\
\text { spraying. }\end{array}$ & $\begin{array}{l}\text { - Ventilation systems installed in } \\
\text { these booths capture up to } 1,465 \\
\mathrm{~kg} / \text { year of these VOC rich emis- } \\
\text { sions. } \\
\text { - Installation of paint spraying and } \\
\text { drying booths requires more elec- } \\
\text { tricity }(46,440 \mathrm{MJ} / \text { year) for paint } \\
\text { application from the base scenario } \\
(1,080 \mathrm{MJ} / \text { year }) \text {. }\end{array}$ & $\begin{array}{c}{[2,768 ; 100]} \\
{[-8,832.6 ; 43 \text { times more }]} \\
{[-32,000 ; 100]}\end{array}$ \\
\hline
\end{tabular}


A sustainability assessment of production process was carried out for an industrial enterprise producing central heating boilers. The manufacture of boilers has several processes including: cutting, bending, welding, cleaning, painting and assembly. For this assessment, bending and assembly are not considered due to a low impact on the sustainability performance of processes.

Relative weights of evaluation criteria were determined using the AHP. The AHP as a method widely applied by researchers [46] was employed for the sustainability assessment of the manufacturing processes of central heating boilers for five main reasons:

- It does not require weights directly assigned to each criteria, all comparisons are made in pairs. The criteria shown in Table 2 cannot be directly aggregated since they are measured in different units. The AHP can be used to resolve this problem because it allows for the data to be normalized and subsequently aggregated.

- The AHP can detect inconsistent judgments and provide an estimate of the degree of inconsistency in the judgments [47].

- The multi-dimensional nature of the method allows us to tackle qualitative problems.

- Results presented in this paper could be accepted because they were derived from eight criteria (activity areas).

A combination of the MCDA and modified AHP was used to identify the assessment of sustainability of boilers manufacturing.

The global sustainability indicator (average impact) of $i$-process $I_{a v i}^{p}$ was established in two steps. First, a local impact indicator $\left(I_{i j}\right)$ was calculated for each activity area within four objectives as presented in Eq. (1):

$$
I_{i j}=I_{\mathrm{TEC} i j}+I_{\mathrm{ENV} i j}+I_{\mathrm{ECO} i j}+I_{\mathrm{ESOC} i j} .
$$

The three resulting measures are the environmental $\left(I_{\mathrm{ENV}}\right)$, social $\left(I_{\mathrm{SOC}}\right)$, technical $\left(I_{\mathrm{TEC}}\right)$, and economic impact $\left(I_{\mathrm{ECO}}\right)$ was obtained using Eqs. (2)-(4) respectively.

$$
\begin{gathered}
I_{\mathrm{ECO} i j}=R_{\mathrm{ECO} i j} \times W i j, \\
I_{\mathrm{TEC} i j}=R_{\mathrm{TEC} i j} \times W i j, \\
I_{\mathrm{ENV} i j}=r_{\mathrm{ENV} i j} \times W i j, \\
I_{\mathrm{SOC} i j}=R_{\mathrm{SOC} i j} \times W i j .
\end{gathered}
$$

Second, the values of indicators $I_{i j}$ were considered as components of sustainability indicator $I_{a v i}^{p}$ presented in Eq. (1). The value of $I_{a v i}^{p}$ was calculated as the sum of the local results $\left(I_{i j}\right)$, multiplied by $n$, where $i$ is number of manufacturing process and $j$ is the number of the activity area, for all processes; $n$ means the number of influencing objectives analyzed

$$
I_{a v i}^{p}=\sum_{i=1}^{n} I_{i j} / n
$$

\section{Applying the developed integrated method in practice}

\section{Identification of sustainability objectives}

Sustainability involves the application of sustainability objectives to manufacturing. The interactions within and across the typical objectives (social environmental, economic) are critical to the understanding of the sustainability manufacturing and measurement indicators [43], because addressing any one of the objectives in isolation could result in unintended consequences [48]. Technical objective is the value offered by the company to customers through its production technology, products. In this context, the paper sets up several indicators which are interlinked within four objectives: technical $\left(I_{\mathrm{TEC}}\right)$, economical $\left(I_{\mathrm{ECO}}\right)$, environmental $\left(I_{\mathrm{ENV}}\right)$ and social $\left(I_{\mathrm{SOC}}\right)$. Interlinked objectives characterize the sustainability (Fig. 1).

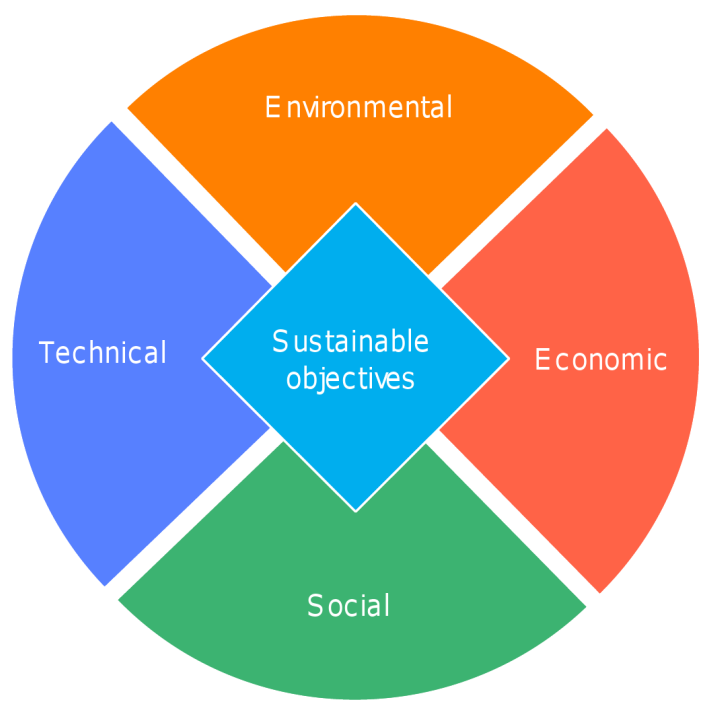

Fig. 1. Four-dimensional sustainability objectives.

Indicators which monitor and assess the environmental performance of the installations when are as follows:

- quantity of air emissions, and their impact on the environment of manufacturing processes; the indicator measures output flows from the installation, such as dust and gases (volatile organic com- 
pounds, carbon dioxide, carbon monoxide, and nitrogen dioxide) or indirectly from energy consumption or transportation,

- materials consumption referring to the operation and maintenance of technologies; material consumption (sand, steel) is among the critical resources used in manufacturing. Some scraps resulting from processes can be used in other processes; they are used to calculate the consumption ratios and factors, which value the resource efficiency on how technologies use these resources,

- energy intensity; the indicator measures input energy flows of the installation. It is used to calculate the energy consumption ratios which value the resource efficiency on how installations use this energy,

- waste (paint, solvents, sand) associated with the amount and type of waste generated; dangerous substances require special treatment in disposal to avoid their negative effect on the environment. Disposal of wasted material and hazardous gases should be also minimized or reduced.

Indicators which assess the technical performance of the installations when are:

- state of technical infrastructure (degree of device wear), reliability, and quality production; applied technologies, equipment should combine the best cost-effective and environmentally friendly solutions,

- installation and user information including consumer information/user instructions for installation, operation and end-of-life management,

- machine longevity (lifetime of the product),

- requirements for technology.

Indicators which evaluate the economic performance of the installations when are as follow:

- implementation costs related to costs for the implementation technological improvements (the investment and production costs) [49],

- energy efficiency: those criteria take into account the technology power efficiency, which in turn affects productivity [50],

- payment to employees,

- environmental management system maintenance referred to audits costs and treatment costs. The treatment costs are represented by the environmental fee for the processing of the functional unit of a ton of industrial waste and emissions.

The social indicators focus on the manpower in the facility (needed employees in entire process to produce the boiler), considering their safety and development. Technical and skill development are necessary requirements for increased company productivity. This could be provided by worker training. Sustainable manufacturing should provide for the well-being of employees and improvement of health through work practices.

Other corresponding indicators criteria can be integrated when they are relevant to specific manufacturing process with specific requirements or deemed to be necessary by individual engineers.

\section{Defining activity areas of manufacturing processes}

Research areas for application of sustainable manufacturing technologies can be broadly categorized into the following activity areas as presented in Table 2. The eight activity areas were evaluated in terms of the four interrelated sustainability objectives (technical, environment, economic, and social). Identification of the activity was based on the literature review $[5,51,52]$.

Figure 2 presents a schematic view of interactions between the sustainability objectives combined with process sustainability criteria (activity areas).

\section{Weighting of activity areas}

Weights need to be suitable for a rapid assessment which means that the activity areas need to match the degree of information offered by experts. More specifically, the activity areas (criteria) need to be easily understandable, and assessment method needs to be easily fulfilled by users having a general knowledge about analyzed companies (focusing on qualitative data).

To set comparable objectives for evaluation, weighting factors can be used to differentiate the impacts of the considered activity areas on the overall judgment. The indicators of the objectives are embodied in activity areas, which are further weighted by using AHP. Weights of the activity areas and corresponding objectives were obtained from an expert in the field of manufacturing. For assessing the relative importance of criteria, Saaty's method [15] was used (Table 3).

According to this scale, the available values for the pair-wise comparisons are members of the set: $\{9,8,7,6,5,4,3,2,1,1 / 2,1 / 3,1 / 4,1 / 5,1 / 6,1 / 7$, $1 / 8,1 / 9\}$. 
Table 2

Activity areas for the sustainability assessment of manufacturing processes.

\begin{tabular}{|c|c|c|}
\hline Activity areas & Factors & References \\
\hline Health \& safety (1) & $\begin{array}{l}\text { Equipment and machinery are kept clean, regularly maintained, enough } \\
\text { work space, cleanliness of operations-exterior and interior, scrap reduc- } \\
\text { tion, minimizing wastes (leaks, fumes and exhaust), noise level reduction, } \\
\text { use of efficient lighting, safety standards for machine tools, environmental } \\
\text { controls, monitoring, remediation, preventive maintenance, work instruc- } \\
\text { tions standard. }\end{array}$ & {$[51,53]$} \\
\hline Production technology state (2) & $\begin{array}{l}\text { Machinery, tooling, material handling, workhandling used, machine per- } \\
\text { formance data availability technology improvement policy, total asset uti- } \\
\text { lization. }\end{array}$ & {$[52,54]$} \\
\hline Production planning (3) & $\begin{array}{l}\text { Capacity planning requirements to ensure that the required materials, } \\
\text { tooling, personnel, and information are available to manufacture the com- } \\
\text { ponents when needed, machines/tools and operating times; production } \\
\text { materials stored at production materials stored at sideline, tools and set- } \\
\text { up equipment kept near the machines, travel distances between processes, } \\
\text { material movement. }\end{array}$ & {$[51,53,55,56]$} \\
\hline $\begin{array}{l}\text { Computer based information sys- } \\
\text { tems in operations planning (4) }\end{array}$ & $\begin{array}{l}\text { Computer systems used to planning of production and management of } \\
\text { activities (to make the effective use of resources, energy and raw materials, } \\
\text { equipment based on order information); the availability of computer and } \\
\text { the system to save the data, transaction, trace the transaction and data, } \\
\text { etc. }\end{array}$ & {$[54]$} \\
\hline Manufacturing empowerment (5) & $\begin{array}{l}\text { Employees involvement in the labor process, cross-functional workforce, } \\
\text { organizational worker power, employee redeployment, educational support } \\
\text { by enhancing sets of skills and expertise, motivation systems. }\end{array}$ & {$[51,57]$} \\
\hline Manufacturing systems (6) & $\begin{array}{l}\text { Manufacturing systems in terms of the type manufacturing process: flow, } \\
\text { intermittent or project manufacturing. }\end{array}$ & \\
\hline $\begin{array}{l}\text { Time-based logistics \& supply } \\
\text { chain system ( } 7)\end{array}$ & $\begin{array}{l}\text { Movement and storage of goods from suppliers to manufacturing and to } \\
\text { final customer; increasing availability of outsourcing, supplier scheduling } \\
\text { and delivery, inventory control, reduced packaging, efficient transporta- } \\
\text { tion, supplier selection. }\end{array}$ & {$[57-59]$} \\
\hline $\begin{array}{l}\text { Quality process } \\
\text { and environmentally-conscious } \\
\text { product design approach (8) }\end{array}$ & $\begin{array}{l}\text { Engineering approach within lean, innovative product development; qual- } \\
\text { ity of conformance, customer attitudes and support for sustainability, im- } \\
\text { plementation of quality best practices. }\end{array}$ & {$[2,58,60]$} \\
\hline
\end{tabular}

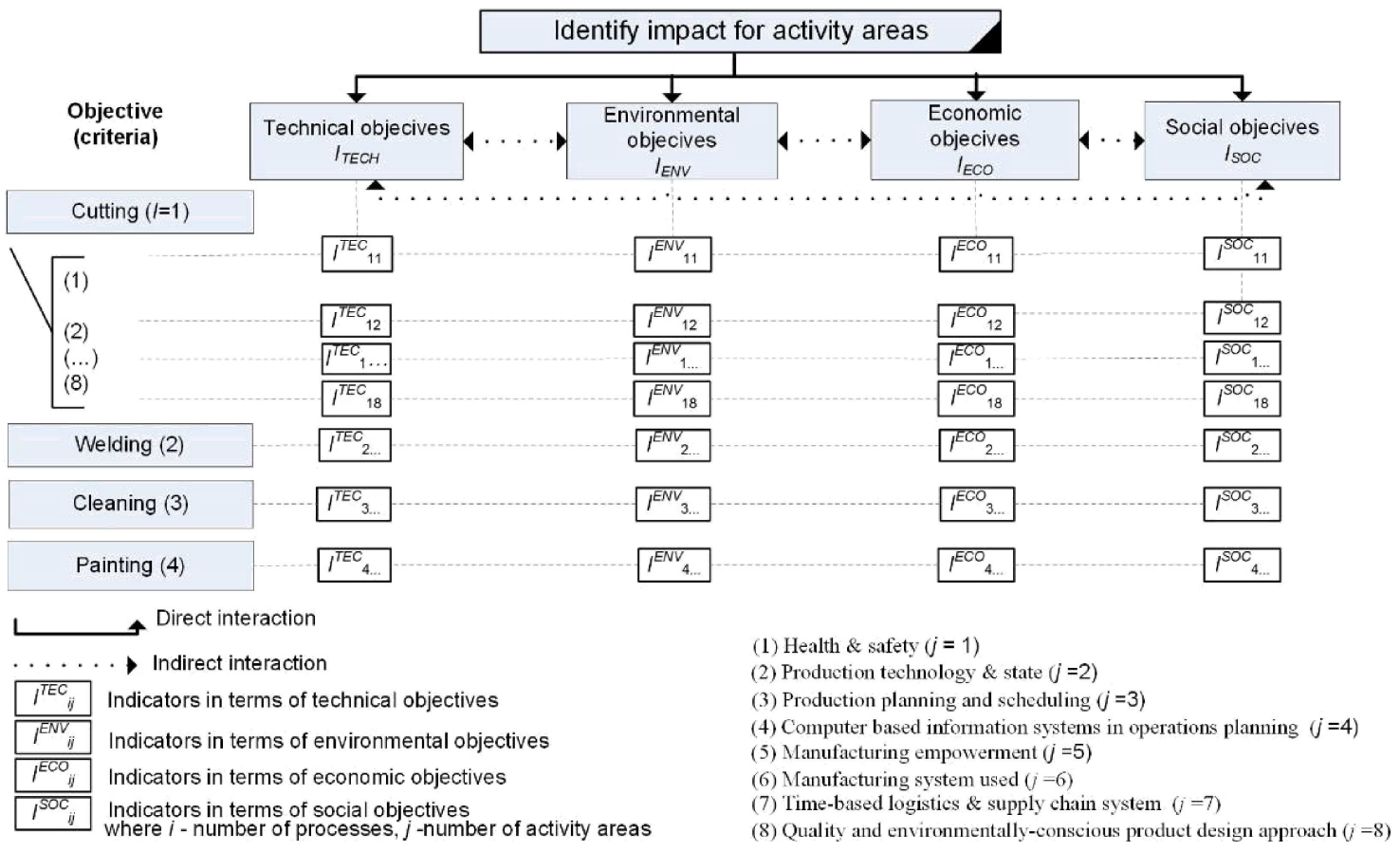

Fig. 2. The framework of multi-criteria approach for processes manufacturing sustainability assessment. 
Table 3

The Saaty's rating scale in AHP method [15].

\begin{tabular}{c|l|l}
\hline Rank & \multicolumn{1}{|c|}{ Definition } & \multicolumn{1}{c}{ Description } \\
\hline 1 & Equal importance & Two factors contribute equally to the objective \\
\hline 3 & Somewhat more important & Experience and judgment slightly favor one over the other \\
\hline 5 & Much more important & Experience and judgment strongly favor one over the other \\
\hline 7 & Verty much more important & Experience and judgment very strongly favor one over the other \\
\hline 9 & Absolutely more important & The evidence favoring one over the other is of the highest possible validity \\
\hline
\end{tabular}

This is achieved through a series of pair-wise comparison matrices A, a simple example of which is depicted in Eq. (2):

$$
A=\left[\begin{array}{cccc}
1 & a_{i j} & \ldots & a_{1 n} \\
\frac{1}{1} & 1 & \ldots & a_{2 n} \\
\ldots & \ldots & 1 & \ldots \\
\frac{1}{a_{1 n}} & \frac{1}{a_{2 n}} & \ldots & 1
\end{array}\right]_{\text {for } i, j=1,2, \ldots, n}
$$

Pairwise comparisons are made by providing a question asking which indicator $i$ or $j$ is more important in the measurement of manufacturing sustainability activity areas of boiler production process.

The following questions are used to establish the weights for criteria: "How important is criterion $A i$ relative to criterion $A j$ ?" or "Which is more important with respect to the criterion? How strongly?" [61]. A matrix of pair-wise comparisons, where the number in the $i$-th row and $j$-th column gives the relative importance of $A i$ to $A j$ (priority vector). The columns of the matrix are normalized by dividing the largest entry in each column. Weights enough to fill in the matrix on the side of the main diagonal, the values on the other side of the main diagonal, they are the opposite of the values lying symmetrically across the diagonal.

All the upper-left to lower-right diagonal elements (for the same criteria) of an analytic hierarchy process comparison matrix are 1's, whereas the values that are diagonal (45 degrees) from each other are the mathematical inverses of each other. As such, they can be calculated from the formula: $a_{j i}=1 / a_{i j}$, where $a_{i j}$ is an assessment of the advantages of the validity of the $i$-th element over the $j$-th.

A case in which pair-wise comparisons are expressed as differences (instead of ratios) was used to define the similarity relations and is described by [62]. Activities in the AHP method can be summarized in four stages [63]:
1. Identifying criteria to compare elements.

2. Gathering value judgments on relative importance of the criteria.

3. Constructing a set of pair-wise comparison matrices (size $n \times n$ ) for each element by using the relative scale measurement described above and their synthesizing. After normalization of all the columns, they are computed to the individual row averages. The received result is the priority vector wj (denoted as the relative importance or weight of $A i$ over $A j)$.

4. Calculating the consistency index CI by using the eigenvalue $\lambda \max$ as follows: $\mathrm{CI}=(\lambda \max -n) /$ $(n-1)$, where $\lambda \max$ is the maximum eigenvalue of the matrix of priorities.

The calculation of the consistency ratio C.R. ensures the consistency of the responses $[64,65]$. The consistency ratios of the matrices was calculated. If C.R. is less than 0.1, then the judgment matrix is consistent. If it is greater, the pairwise comparisons should be re-evaluated. The last column of each matrix represents the eigenvectors indicating the absolute priority weight of each rated activity areas.

Figures $3-6$ show the relative weights and C.R. values for the activity areas with respect to the objectives.

\begin{tabular}{c|cccccccc|c}
$\mathrm{R}_{\mathrm{EN}}$ & $(1)$ & $(2)$ & $(3)$ & $(4)$ & $(5)$ & $(6)$ & $(7)$ & $(8)$ & $\mathbf{E V}$ \\
\hline$(1)$ & 1 & 3 & 5 & 5 & 9 & 5 & 9 & 5 & 0.37 \\
$(2)$ & $1 / 3$ & 1 & 3 & 3 & 5 & 7 & 7 & 5 & 0.23 \\
$(3)$ & $1 / 5$ & $1 / 3$ & 1 & 3 & 3 & 3 & 3 & 1 & 0.11 \\
$(4)$ & $1 / 5$ & $1 / 3$ & $1 / 3$ & 1 & 5 & 3 & 3 & 3 & 0.10 \\
$(5)$ & $1 / 9$ & $1 / 5$ & $1 / 3$ & $1 / 5$ & 1 & $1 / 3$ & 3 & $1 / 3$ & 0.04 \\
$(6)$ & $1 / 5$ & $1 / 7$ & $1 / 3$ & $1 / 3$ & 3 & 1 & 3 & 3 & 0.07 \\
$(7)$ & $1 / 9$ & $1 / 7$ & $1 / 3$ & $1 / 3$ & $1 / 3$ & $1 / 3$ & 1 & $1 / 3$ & 0.03 \\
$(8)$ & $1 / 5$ & $1 / 5$ & 1 & $1 / 3$ & 3 & $1 / 3$ & $1 / 7$ & 1 & 0.06
\end{tabular}

Note: $\lambda \max =8.79 \quad \mathrm{RI}=1.41 \quad \mathrm{CI}=0.080$ C.R. $=0.08$

Fig. 3. Criteria with respect to $I_{\mathrm{ENV}}$. 


\begin{tabular}{r|cccccccc|c}
$\mathrm{R}_{\mathrm{TE}}$ & $(1)$ & $(2)$ & $(3)$ & $(4)$ & $(5)$ & $(6)$ & $(7)$ & $(8)$ & $\mathbf{E V}$ \\
\hline$(1)$ & 1 & 3 & 3 & 3 & 7 & 9 & 3 & 7 & 0.31 \\
$(2)$ & $1 / 3$ & 1 & 5 & 5 & 9 & 7 & 7 & 9 & 0.30 \\
$(3)$ & $1 / 3$ & $1 / 5$ & 1 & 3 & 3 & 5 & 3 & 5 & 0.14 \\
$(4)$ & $1 / 5$ & $1 / 5$ & $1 / 3$ & 1 & 3 & 3 & $1 / 3$ & 3 & 0.07 \\
$(5)$ & $1 / 7$ & $1 / 9$ & $1 / 3$ & $1 / 9$ & 1 & 3 & 3 & $1 / 3$ & 0.05 \\
$(6)$ & $1 / 9$ & $1 / 7$ & $1 / 5$ & $1 / 9$ & $1 / 3$ & 1 & 3 & $1 / 3$ & 0.04 \\
$(7)$ & $1 / 7$ & $1 / 7$ & $1 / 9$ & $1 / 9$ & $1 / 3$ & $1 / 3$ & 1 & $1 / 3$ & 0.03 \\
$(8)$ & $1 / 7$ & $1 / 9$ & $1 / 5$ & $1 / 3$ & 3 & 3 & 3 & 1 & 0.06
\end{tabular}

Note: $\lambda \max =8.79 \quad \mathrm{RI}=1.41 \quad \mathrm{CI}=0.080$ C.R. 0.081

Fig. 4. Criteria with respect to $I_{\mathrm{TEC}}$.

\begin{tabular}{c|cccccccc|c}
$\mathrm{R}_{\mathrm{ECO}}$ & $(1)$ & $(2)$ & $(3)$ & $(4)$ & $(5)$ & $(6)$ & $(7)$ & $(8)$ & $\mathrm{EV}$ \\
\hline$(1)$ & 1 & $1 / 5$ & $1 / 3$ & $1 / 3$ & 3 & 3 & 5 & 3 & 0.11 \\
$(2)$ & 5 & 1 & 3 & 3 & 3 & 9 & 7 & 5 & 0.34 \\
$(3)$ & 3 & $1 / 3$ & 1 & 3 & 5 & 7 & 5 & 3 & 0.22 \\
$(4)$ & $1 / 3$ & $1 / 3$ & $1 / 3$ & 1 & 3 & 3 & 3 & 3 & 0.11 \\
$(5)$ & $1 / 3$ & $1 / 3$ & $1 / 5$ & $1 / 3$ & 1 & 3 & $1 / 9$ & $1 / 5$ & 0.05 \\
$(6)$ & $1 / 3$ & $1 / 9$ & $1 / 7$ & $1 / 3$ & $1 / 3$ & 1 & $1 / 3$ & 3 & 0.05 \\
$(7)$ & $1 / 5$ & $1 / 7$ & $1 / 5$ & $1 / 3$ & $1 / 3$ & $1 / 3$ & 1 & $1 / 5$ & 0.03 \\
$(8)$ & $1 / 3$ & $1 / 5$ & $1 / 3$ & $1 / 3$ & 5 & $1 / 3$ & 5 & 1 & 0.09
\end{tabular}

Note: $\lambda \max =8.89 \quad \mathrm{RI}=1.41 \quad \mathrm{CI}=0.127$ C.R. $=0.09$

Fig. 5. Criteria with respect to $I_{\mathrm{ECO}}$.

\begin{tabular}{c|cccccccc|c}
$\mathrm{R}_{\mathrm{Sod}}$ & $(1)$ & $(2)$ & $(3)$ & $(4)$ & $(5)$ & $(6)$ & $(7)$ & $(8)$ & $\mathrm{EV}$ \\
\hline$(1)$ & 1 & 3 & 5 & 3 & $1 / 3$ & 3 & 3 & 3 & 0.19 \\
$(2)$ & $1 / 3$ & 1 & 5 & 5 & $1 / 3$ & 3 & 3 & 3 & 0.15 \\
$(3)$ & $1 / 5$ & $1 / 5$ & 1 & 3 & $1 / 5$ & $1 / 3$ & 1 & 3 & 0.06 \\
$(4)$ & $1 / 3$ & $1 / 5$ & $1 / 3$ & 1 & $1 / 9$ & $1 / 3$ & 1 & 3 & 0.05 \\
$(5)$ & 3 & 3 & 5 & 9 & 1 & 5 & 7 & 7 & 0.36 \\
$(6)$ & $1 / 3$ & $1 / 3$ & 3 & 3 & $1 / 5$ & 1 & 5 & 3 & 0.11 \\
$(7)$ & $1 / 3$ & $1 / 3$ & 1 & 1 & $1 / 7$ & $1 / 5$ & 1 & 3 & 0.05 \\
$(8)$ & $1 / 3$ & $1 / 3$ & $1 / 3$ & $1 / 3$ & $1 / 7$ & $1 / 3$ & $1 / 3$ & 1 & 0.03
\end{tabular}

Note: $\lambda \max =8.91 \quad \mathrm{RI}=1.41 \quad \mathrm{CI}=0.131$ C.R. $=0.09$

Fig. 6. Criteria with respect to $I_{\mathrm{SOC}}$.

Defined priority weights are the same for both scenarios: baseline and improvement.

\section{Degree of sustainability for production process}

The possible future sustainability assessment of manufacturing processes was described in Table 4 .
Baseline scenario for manufacturing is developed without a focus on sustainability. Investments in technologies and corresponding improvement have typically been driven by increased productivity, reduced operating costs and work effort, and enforced environmental regulatory compliance. Improvement scenario is likely to be based on meeting facility needs, increasing the utilization efficiency of energy, materials and related manufacturing technology in order to improve environmental process quality and the future business prospects for the company.

The five Likert scale was used for sustainability assessment of manufacturing, where 5 indicates the highest degree of sustainability and 1 indicates the lowest degree of sustainability. Likert scale shows the respondent opinion, quick and easy to made, more reliable, and give many data.

The judgments from individual experts were then synthesized into a single judgment through geometric mean in order to get an overall estimate of the priorities/importance for each criterion in terms of the sustainability objectives. Indicators with a value of more than 3 were selected for inclusion in the improvement model. The geometric mean for synthesizing individual judgments was expressed in Eq. (8):

$$
G M\left(a_{1}, a_{2}, a_{3}\right)=\left(a_{1} x a_{2} x a_{3}\right)^{1 / 3},
$$

where $\mathrm{GM}=$ Geometric mean, Likert scale given by an expert, $n=$ Number of experts.

Figure 7 shows the matrices containing the individual judgments from the experts in the baseline scenario. The values of geometric means for the manufacturing process across the technical, environmental, economic and social objective are calculated similarly. Table 5 presents a matrix with synthesizing the judgments (GM) from the experts for both scenarios.

The impact values $\left(I_{\mathrm{ENV}}, I_{\mathrm{ECO}}, I_{\mathrm{SOC}}, I_{\mathrm{TECH}}\right)$ for particular objectives were rated on a scale of $0-5$.

The values for $I_{i j}$ across all activity areas within each manufacturing process can be evaluated in the horizontal rows for particular sustainability objectives by summing the scores of all influencing sustainability objectives, and then to calculate the value of global sustainability indicators for all processes. 


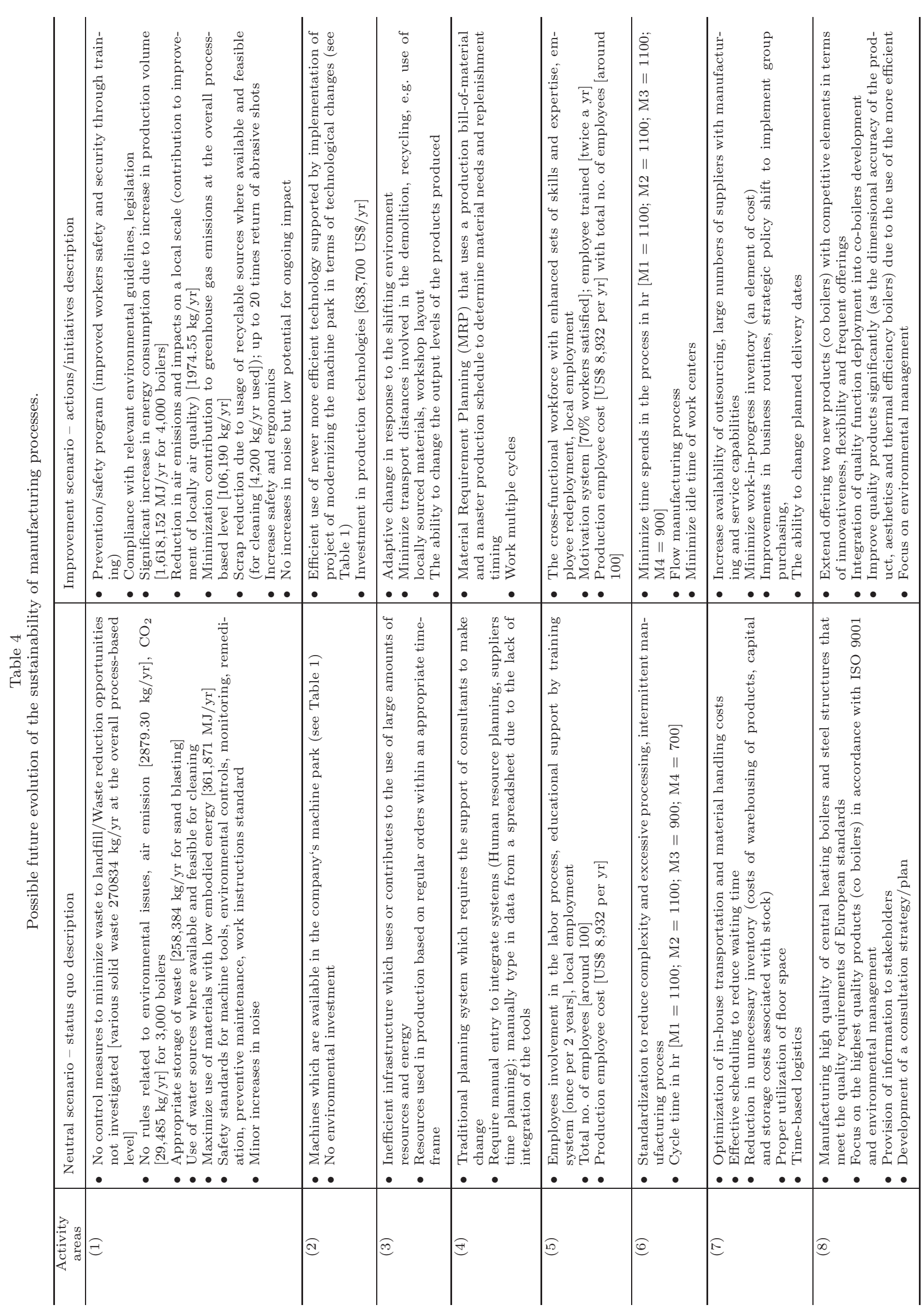


Management and Production Engineering Review

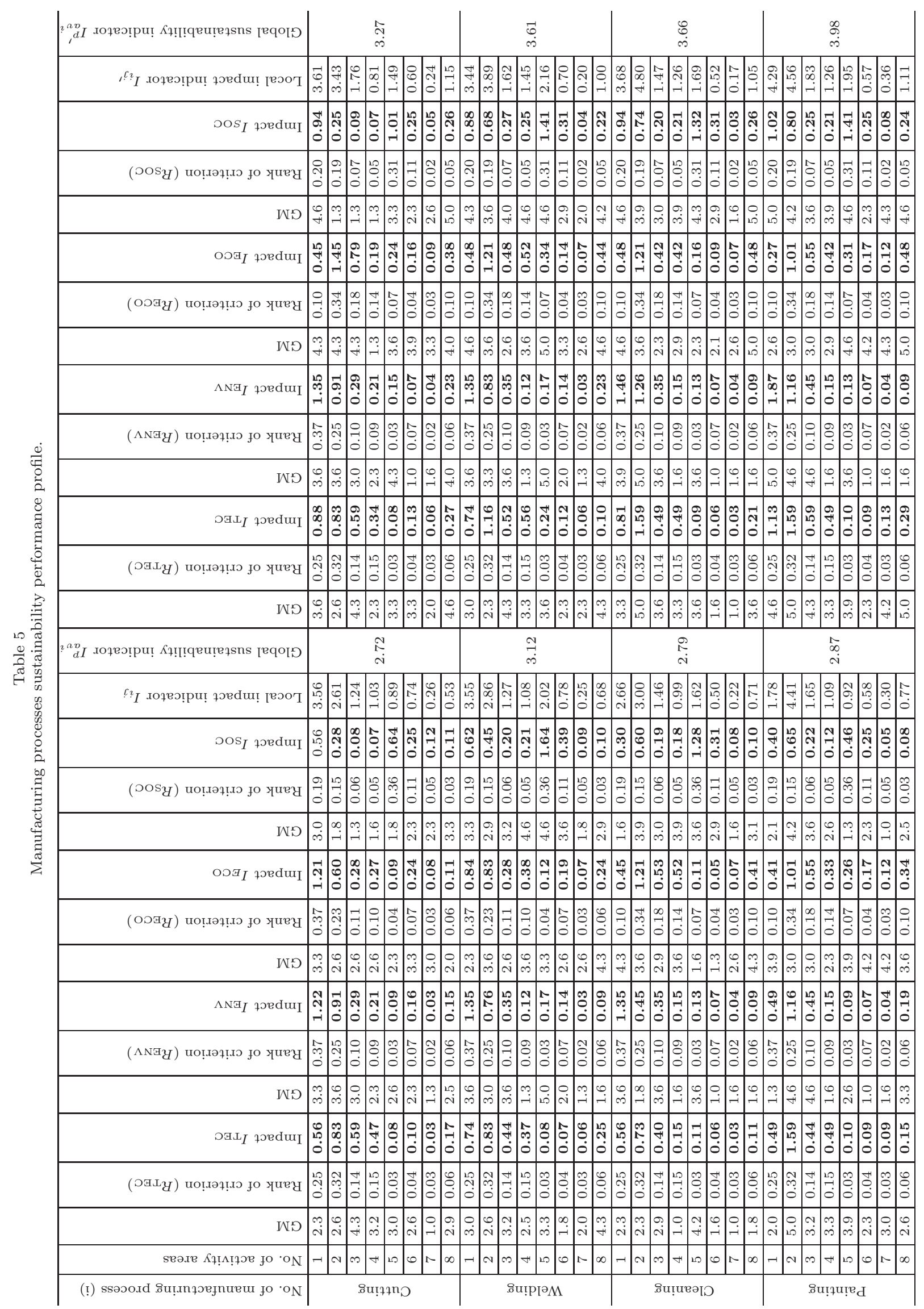




\begin{tabular}{|c|c|c|c|c|c|c|c|c|}
\hline$I_{11}^{p}$ & $I_{T E C}$ & $G M$ & $I_{E N V}$ & GM & $I_{E C O}$ & GM & $I_{S O C}$ & $G M$ \\
\hline $\mathrm{C} 1$ & $(2 ; 2 ; 3)$ & 2.3 & $(4 ; 3 ; 3)$ & 3.3 & $(3 ; 3 ; 4)$ & 3.3 & $(3 ; 3 ; 3)$ & 3.0 \\
\hline $\mathrm{C} 2$ & $(3 ; 2 ; 3)$ & 2.6 & $(4 ; 3 ; 4)$ & 3.6 & $(3 ; 3 ; 2)$ & 2.6 & $(1 ; 3 ; 2)$ & 1.8 \\
\hline $\mathrm{C} 3$ & $(4 ; 4 ; 5)$ & 4.3 & $(3 ; 3 ; 3)$ & 3.0 & $(3 ; 3 ; 2)$ & 2.6 & $(2 ; 1 ; 1)$ & 1.3 \\
\hline $\mathrm{C} 4$ & $(4 ; 2 ; 4)$ & 3.2 & $(2 ; 2 ; 3)$ & 2.3 & $(3 ; 2 ; 3)$ & 2.6 & $(2 ; 2 ; 1)$ & 1.6 \\
\hline $\mathrm{C} 5$ & $(3 ; 3 ; 3)$ & 3.0 & $(3 ; 3 ; 2)$ & 2.6 & $(3 ; 2 ; 2)$ & 2.3 & $(2 ; 1 ; 3)$ & 1.8 \\
\hline C6 & $(3 ; 2 ; 3)$ & 2.6 & $(2 ; 2 ; 3)$ & 2.3 & $(3 ; 4 ; 3)$ & 3.3 & $(2 ; 2 ; 3)$ & 2.3 \\
\hline C7 & $(1 ; 1 ; 1)$ & 1.0 & $(1 ; 2 ; 1)$ & 1.3 & $(3 ; 3 ; 3)$ & 3.0 & $(3 ; 2 ; 2)$ & 2.3 \\
\hline $\mathrm{C} 8$ & $(4 ; 3 ; 2)$ & 2.9 & $(4 ; 2 ; 2)$ & 2.5 & $(4 ; 2 ; 1)$ & 2.0 & $(3 ; 3 ; 4)$ & 3.3 \\
\hline$I_{12}{ }^{p}$ & $I_{T E C}$ & $G M$ & $I_{E N V}$ & $G M$ & $I_{E C O}$ & $G M$ & $I_{S O C}$ & $G M$ \\
\hline $\mathrm{C} 1$ & $(3 ; 3 ; 3)$ & 3.0 & $(3 ; 4 ; 4)$ & 3.6 & $(2 ; 2 ; 3)$ & 2.3 & $(3 ; 4 ; 3)$ & 3.3 \\
\hline $\mathrm{C} 2$ & $(3 ; 2 ; 3)$ & 2.6 & $(3 ; 3 ; 3)$ & 3.0 & $(3 ; 4 ; 4)$ & 3.6 & $(4 ; 3 ; 2)$ & 2.9 \\
\hline $\mathrm{C} 3$ & $(4 ; 4 ; 2)$ & 3.2 & $(4 ; 4 ; 3)$ & 3.6 & $(3 ; 3 ; 2)$ & 2.6 & $(4 ; 2 ; 4)$ & 3.2 \\
\hline $\mathrm{C} 4$ & $(4 ; 2 ; 2)$ & 2.5 & $(1 ; 2 ; 1)$ & 1.3 & $(3 ; 4 ; 4)$ & 3.6 & $(4 ; 5 ; 5)$ & 4.6 \\
\hline $\mathrm{C} 5$ & $(3 ; 4 ; 3)$ & 3.3 & $(5 ; 5 ; 5)$ & 5.0 & $(4 ; 3 ; 3)$ & 3.3 & $(5 ; 4 ; 5)$ & 4.6 \\
\hline C6 & $(2 ; 1 ; 3)$ & 1.8 & $(2 ; 2 ; 2)$ & 2.0 & $(3 ; 2 ; 3)$ & 2.6 & $(4 ; 4 ; 3)$ & 3.6 \\
\hline C7 & $(2 ; 2 ; 2)$ & 2.0 & $(1 ; 1 ; 2)$ & 1.3 & $(3 ; 3 ; 2)$ & 2.6 & $(3 ; 2 ; 1)$ & 1.8 \\
\hline C8 & $(4 ; 4 ; 5)$ & 4.3 & $(1 ; 2 ; 2)$ & 1.6 & $(4 ; 5 ; 4)$ & 4.3 & $(4 ; 3 ; 2)$ & 2.9 \\
\hline$I_{13}^{p}$ & $I_{T E C}$ & $G M$ & $I_{E N V}$ & $G M$ & $I_{E C O}$ & $G M$ & $I_{S O C}$ & $G M$ \\
\hline $\mathrm{C} 1$ & $(2 ; 2 ; 3)$ & 2.3 & $(3 ; 5 ; 3)$ & 3.6 & $(4 ; 4 ; 5)$ & 4.3 & $(2 ; 2 ; 1)$ & 1.6 \\
\hline $\mathrm{C} 2$ & $(2 ; 2 ; 3)$ & 2.3 & $(1 ; 2 ; 3)$ & 1.8 & $(3 ; 4 ; 4)$ & 3.6 & $(3 ; 4 ; 5)$ & 3.9 \\
\hline $\mathrm{C} 3$ & $(2 ; 3 ; 4)$ & 2.9 & $(4 ; 4 ; 3)$ & 3.6 & $(3 ; 2 ; 4)$ & 2.9 & $(3 ; 3 ; 3)$ & 3.0 \\
\hline $\mathrm{C} 4$ & $(1 ; 1 ; 1)$ & 1.0 & $(2 ; 2 ; 1)$ & 1.6 & $(3 ; 4 ; 4)$ & 3.6 & $(4 ; 3 ; 5)$ & 3.9 \\
\hline $\mathrm{C} 5$ & $(5 ; 5 ; 3)$ & 4.2 & $(3 ; 5 ; 3)$ & 3.6 & $(1 ; 2 ; 2)$ & 1.6 & $(4 ; 4 ; 3)$ & 3.6 \\
\hline C6 & $(2 ; 2 ; 1)$ & 1.6 & $(1 ; 1 ; 1)$ & 1.0 & $(2 ; 1 ; 1)$ & 1.3 & $(4 ; 2 ; 3)$ & 2.9 \\
\hline C7 & $(1 ; 1 ; 1)$ & 1.0 & $(1 ; 2 ; 2)$ & 1.6 & $(3 ; 3 ; 2)$ & 2.6 & $(1 ; 2 ; 2)$ & 1.6 \\
\hline $\mathrm{C} 8$ & $(3 ; 1 ; 2)$ & 1.8 & $(2 ; 1 ; 2)$ & 1.6 & $(4 ; 4 ; 5)$ & 4.3 & $(5 ; 2 ; 3)$ & 3.1 \\
\hline$I_{14}{ }^{p}$ & $I_{T E C}$ & $G M$ & $I_{E N V}$ & $G M$ & $I_{E C O}$ & $G M$ & $I_{S O C}$ & $G M$ \\
\hline $\mathrm{C} 1$ & $(1 ; 2 ; 4)$ & 2.0 & $(2 ; 1 ; 1)$ & 1.3 & $(3 ; 4 ; 5)$ & 3.9 & $(3 ; 1 ; 3)$ & 2.1 \\
\hline $\mathrm{C} 2$ & $(5 ; 5 ; 5)$ & 5.0 & $(4 ; 5 ; 5)$ & 4.6 & $(3 ; 3 ; 3)$ & 3.0 & $(3 ; 5 ; 5)$ & 4.2 \\
\hline $\mathrm{C} 3$ & $(4 ; 2 ; 4)$ & 3.2 & $(4 ; 5 ; 5)$ & 4.6 & $(3 ; 3 ; 3)$ & 3.0 & $(3 ; 5 ; 3)$ & 3.6 \\
\hline $\mathrm{C} 4$ & $(4 ; 3 ; 3)$ & 3.3 & $(2 ; 2 ; 1)$ & 1.6 & $(3 ; 2 ; 2)$ & 2.3 & $(3 ; 3 ; 2)$ & 2.6 \\
\hline C5 & $(5 ; 4 ; 3)$ & 3.9 & $(3 ; 2 ; 3)$ & 2.6 & $(4 ; 3 ; 5)$ & 3.9 & $(1 ; 2 ; 1)$ & 1.3 \\
\hline C6 & $(3 ; 4 ; 1)$ & 2.3 & $(1 ; 1 ; 1)$ & 1.0 & $(3 ; 5 ; 5)$ & 4.2 & $(2 ; 2 ; 3)$ & 2.3 \\
\hline C7 & $(3 ; 3 ; 3)$ & 3.0 & $(2 ; 1 ; 2)$ & 1.6 & $(5 ; 3 ; 5)$ & 4.2 & $(1 ; 1 ; 1)$ & 1.0 \\
\hline $\mathrm{C} 8$ & $(2 ; 3 ; 3)$ & 2.6 & $(3 ; 3 ; 4)$ & 3.3 & $(3 ; 5 ; 3)$ & 3.6 & $(4 ; 2 ; 2)$ & 2.5 \\
\hline
\end{tabular}

Fig. 7. Decision makers' opinion of category importance weight for the baseline scenario.

\section{Sustainability assessment and improvements}

One goal of sustainability characterization methodology is to improve the manufacturing sustainability performance [14]. Figure 8 indicates the overall methodology adopted in this study.

The evaluation results properly reflected the problems in the actual manufacturing processes and provided rational and specify guidance for developing new manufacturing technologies or replacing existing ones in this firm (sustainability improvement). Based on the assessment results, specific technological changes and practices were adopted including replacing plasma cutter with laser cutter adding filtered ventilation system device to sawing machine, applying sand blasting equipment with shot-blasting booth with a closed abrasive circuit system, equipped with integral filter system to reduce dust, installing of the paint spraying and drying cabins with air re- circulation loop, designing of push - pull welding ventilation for welding. With these technologies and management improvement, it was found that the effectiveness of the case company was improved.

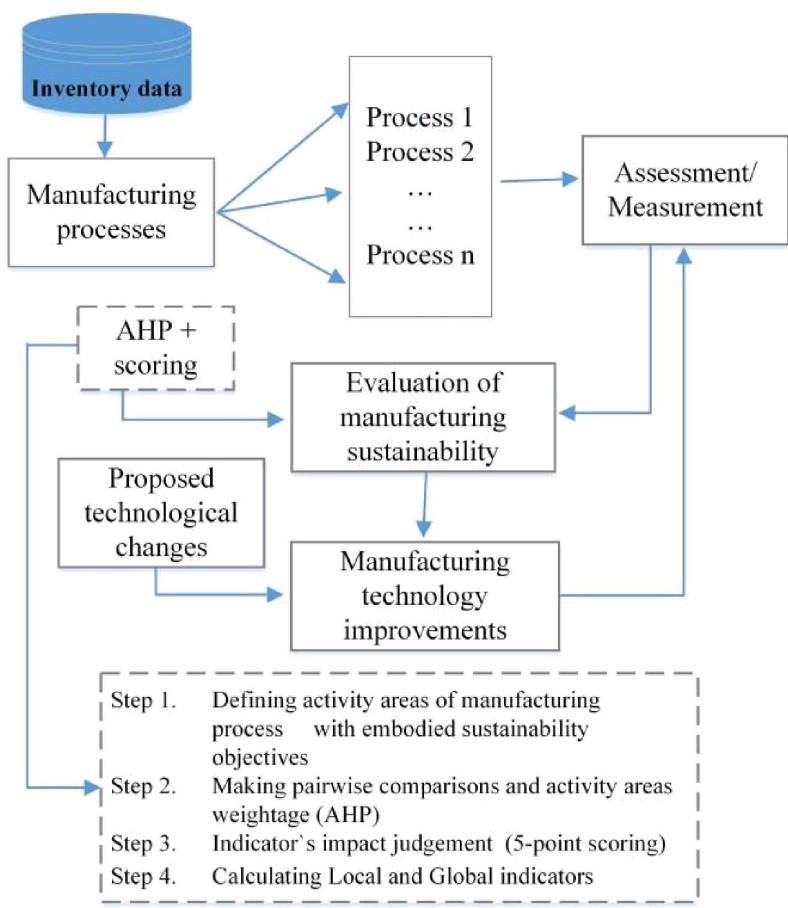

Fig. 8. Methodology for sustaiability assessment and improvement for manufacturing process adopted in this study.

The accuracy of the "weights scale" was tested by statistical methods. The scale reliability of manufacturing sustainability $\alpha$-Cronbach amounted to 0.789 and mean of all the Pearson's correlation coefficients was 0.484 . The correlation matrix indicated that the last variable was least correlated with the other items. It can also examine the scoring scale of the manufacturing technologies used in the context of sustainable growth of the enterprise.

The scoring scale turned out to be a reliable scale. Cronbach alpha coefficient was 0.682 .

Table 5 shows an example of a convenient sustainability assessment method for manufacturing processes based on the eight activity areas depicted in Table 2 with the rating system as follows: score of 1-2 represents a poor degree of the sustainability, 2-3 - moderate, 3-4 - significant, and 4-5 very significant sustainability impact.

From the Fig. 9, it can be observed that the local indicators $I_{i j}$ for individual activity areas in the improvement scenario are higher than the baseline one for all manufacturing processes. 

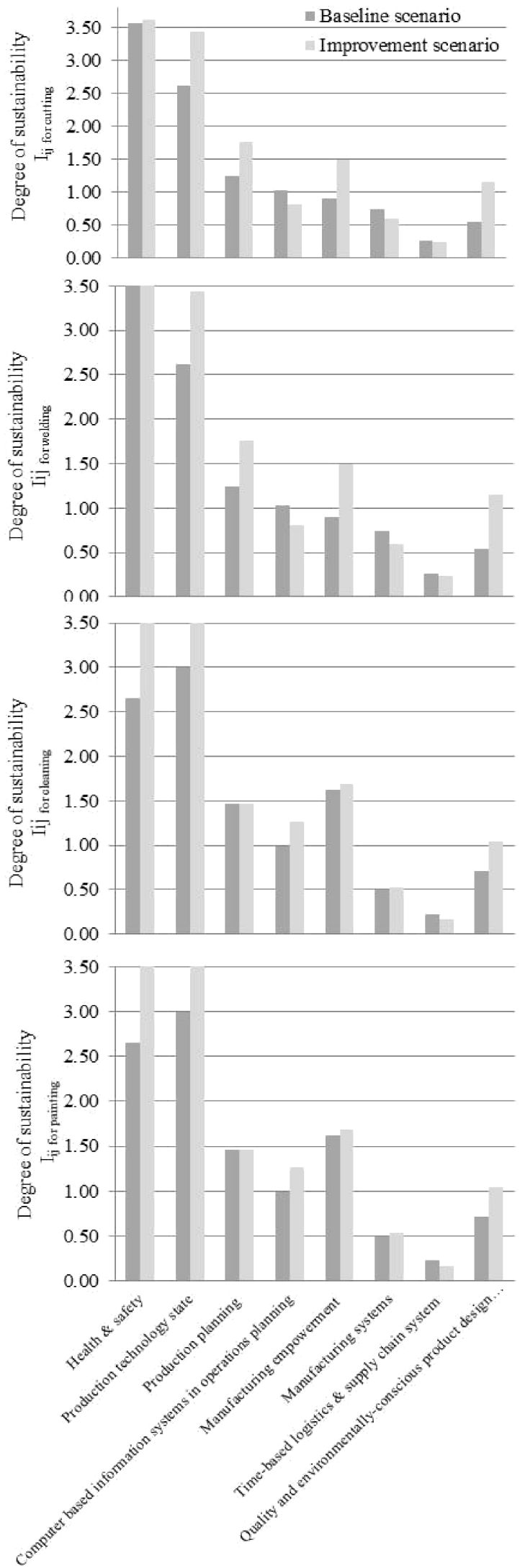

Fig. 9. Local indicators, $I_{i j}$, individual of the activity areas compared baseline and improvement scenario.
Experts emphasized need for substantial improvement in the performance of activity areas, especially in manufacturing systems and time - based logistics and supply chain system.

The applicability and usability of the proposed assessment method was verified by the case study in company producing heating devices.

The eight activity areas indices of the manufacturing processes were compared within both scenarios (Fig. 9). Then, the following information could be deduced:

- Health \& safety $\left(I_{i 1}\right)$ for painting had been seen a considerable increase in its degree of the sustainability level (from 1.78 to 4.29 ). The production technology state also obviously improved (from 4.41 to 4.56 ), for cutting the indicator increased drastically from level of 3.0 to 4.80 in this activity area.

Compared to other activity areas, health \& safety as well as production technology state are the highest in all processes because these criteria are more on sustainability and can significantly contribute to environmental and economic sustainability.

- Two indicators designed for production planning and scheduling $\left(I_{i 3}\right)$ and computer based information systems in operations planning $\left(I_{i 4}\right)$ showed the poor level where they were compared in the improvement scenario. The indicators still had room for improvement because their rates were between 1 and 2 (a modest degree of the sustainability).

- The company has not paid much attention to these indicators in the baseline scenario, because weights of manufacturing processes to the improvement scenario were small. Only with respect to the indicators $\left(I_{i 7}\right)$ and $\left(I_{i 8}\right)$, the degree of sustainability level decreased slightly in all process when compared with the improvement scenario. It indicated that the company's activities for improving these areas (manufacturing systems and time-based logistics) had not a significant improvement rate.

There rest of activity areas are not slightly higher than the others.

The global sustainability indicator $I_{a v}^{p}$ of welding is not slightly higher than the process in the improvement scenario showing $16 \%$ of improvement. The biggest (significant) improvement is represented by painting (40\%), then cleaning (30\%), and cutting $(19 \%)$.

Although the global indicators corresponding to manufacturing processes had great progress by means of implementing some technological solutions, it was still far from reaching very significant sustainability degree in manufacturing. 


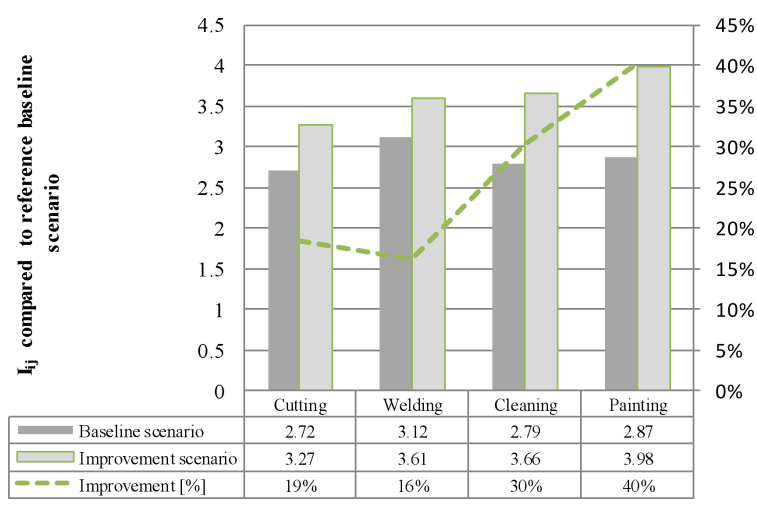

Fig. 10. Global sustainability indicator, $I_{a v}^{p}$, individual of the company compared baseline and improvement scenario.

\section{Discussion and conclusions}

The paper led to "rough" sustainability assessment of the manufacturing processes due to limited data which appear to be a characteristic of the case study presented The presented assessment tool constitutes an initial development of an infrastructure - a framework for sustainability performance measurement. The proposed framework for sustainability assessment of manufacturing processes is based on the AHP method covering the four dimensions of sustainability.

To achieve consistency with similar efforts, a unified classification of activity areas was applied for process sustainability characterization.

However, some limitations should be addressed. Firstly, the study was based on a single case study. Secondly, the methodology used which was based on limited data available in the plant. The collection of data from experts may bias the results leading to different results. Third, it provided limited ground to generalize the findings. This suggests the need to replicate and extend the research for greater understanding of each activity area and to develop appropriate indicators.

This approach seems particularly useful when comparing different processes within the production. It makes applicable for various industries and might be a challenge to derive priorities for systematic improvement. It also seems to be promising method for reducing the computational times involved.

Future work will focus on refining the methods.

\section{References}

[1] Rosen M.A., Kishawy H.A., Sustainable manufacturing and design: concepts, practices and needs, Sustainability, 4, 154-174, 2012.
[2] Goyal P., Rahman Z., Corporate sustainability performance assessment: an analytical hierarchy process approach, Int. J. Intercultural Information Management, 4, 1, 1-14, 2014.

[3] STPI (Science and Technology Policy Institute), White Papers on Advanced Manufacturing Questions. Advanced Manufacturing Workshop of the President's Council of Advisors on Science and Technology's Study on Creating New Industries through Science, Technology, and Innovation, Science and Technology, Science and Technology Policy Institute, Washington D.C., 2014.

[4] Geldermann J., Rentz O., Multi-criteria analysis for technique assessment case study from industrial coating, Journal of Industrial Ecology, 9, 3, 127-142, 2005 .

[5] Buckley G., Henriques M., Salazar-Xirinach J.M., The promotion of sustainable enterprises, International Labour Organization, Geneva, 2009.

[6] Van der Heijden A., Driessen P.P.J., Cramer J.M., Making sense of corporate social responsibility: exploring organizational processes and strategies, Journal of Cleaner Production, 18, 1787-1796, 2010.

[7] Savitz A.W., Weber K., The triple bottom line, Jossey Bass, San Francisco, 2006.

[8] Sutherland J.W., Rivera J.L., Brown K.L., Law M., Hutchins M.J., Jenkins, T.L., Haapala K.R., Manufacturing systems and technologies for the new frontier, Challenges for the Manufacturing Enterprise to Achieve Sustainable Development, 2008.

[9] Hauff M., Wilderer P.A., Industrial ecology: engineered representation of sustainability, Sustainability Science, 3, 103-115, 2008.

[10] Lu T., Gupta A., Jayal A.D., Badurdeen F., Feng S.C., Jr O.W.D., Jawahir I.S., A framework of product and process metrics for sustainable manufacturing, [in:] Advances in Sustainable Manufacturing, G. Seliger, M.M.K. Khraisheh and I.S. Jawahir [Eds.], Berlin Heidelberg: Springer, pp. 333-338, 2011.

[11] Reich-Weiser C., Vijayaraghavan A., Dornfeld D., Metrics for sustainable manufacturing, Proceedings of the 2008 International Manufacturing Science and Engineering Conference, Illinois, October 2008.

[12] Jawahir I.S., Badurdeen F., Assessment of product and process sustainability: towards developing metrics for sustainable manufacturing, Proceedings of the NIST Workshop on Sustainable Manufacturing, NIST, Washington D.C, 2009.

[13] Zhang H., Haapala K.R., Integrating sustainable manufacturing assessment into decision making for a production work cell, Journal of Cleaner Production, 105, 52-63, 2015. 
[14] Mani M., Madan J., Leeb J.H., Lyons K.W., Gupta S.K., Sustainability characterization for manufacturing processes, International Journal of Production Research, 52, 20, 5895-5912, 2014.

[15] Saaty T.L., Analytic hierarchy process, McGrawHill, New York, 1980.

[16] Chan F.T.S., Interactive selection model for supplier selection process: an analytical hierarchy process approach, International Journal Production Research, 41, 15, 3549-3579, 2003.

[17] Cinelli M., Coles S.R., Kirwan K., Analysis of the potentials of multi criteria decision analysis methods to conduct sustainability assessment, Ecological Indicators, 46, 138-148, 2014.

[18] Despeisse M., Mbaye F., Ball P.D., Levers A., The emergence of sustainable manufacturing practices, Production Planning \& Control, 23, 5, 354-376, 2012.

[19] Kluczek A., Application of best available techniques in an enterprise producing heating devices, Journal of Cleaner Production, 83, 444-45, 2014.

[20] Chen D., Thiede S., Schudeleit T., Herrmann C., A holistic and rapid sustainability assessment tool for manufacturing SMEs, CIRP Annals-Manufacturing Technology, 63, 437-44, 2014.

[21] Guang X., Wang Y., Tao L., Machining scheme selection of digital manufacturing based on genetic algorithm and AHP, Journal of Intelligent Manufacturing, 20, 6, 661-669, 2009.

[22] Vaidya O.S., Kumar S., Analytic hierarchy process: an overview of applications, European Journal of Operational Research, 169, 1-29, 2006.

[23] Vargas R.V., Using the analytic hierarchy process $(A H P)$ to select and prioritize projects in portfolio, 2010-North America, PMI Global Congress, Washington, 2010.

[24] Keeney R.L., Raiffa, H., Decisions with multiple objectives: preferences and value tradeoffs, New York, Wiley, 1993.

[25] Hermann B.G., Kroeze C., Jawjit W., Assessing environmental performance by combining life cycle assessment, multi-criteria analysis and environmental performance indicators, Journal of Cleaner Production, 15, 1787-1796, 2007.

[26] Khalili N.R., Duecker S., Application of multicriteria decision analysis in design of sustainable environmental management system framework, Journal of Cleaner Production, 47, 188-198, 2013.

[27] Steele K., Carmel Y., Cross J., Wilcox C., Uses and misuses of multi-criteria decision analysis (MCDA) in environmental decision-making, Risk Analysis, 29, 1, 26-33, 2009.

[28] Triantaphyllou E., Baig K., The impact of aggregating benefit and cost criteria in four MCDA methods, Engineering Management, IEEE Transactions on, 52, 2, 213-226, 2005.

[29] Liu F.H.F., Hai H.L., The voting analytic hierarchy process method for selecting supplier, International Journal of Production Economics, 97, 3, 308-317, 2005 .

[30] Kornfeld B., Kara S., Project portfolio selection in continuous improvement, International Journal of Operations \& Production Management, 31, 10, 1071-1088, 2011.

[31] Dimache E., Roche T., A decision methodology to support servitisation of manufacturing, International Journal of Operations \& Production Management, 33, 11/12, 1435-1457, 2012.

[32] Martinsuo M., Project portfolio management in practice and in context, International Journal of Project Management, 31, 6, 794-803, 2013.

[33] Kłos S., Trebiina P., Using the AHP method to select an ERP system for an SME manufacturing company, Management and Production Engineering Review, 5, 3, 14-22, 2014 .

[34] Varela L.R., Ribeiro R.A., Evaluation of simulated annealing to solve fuzzy optimization problems, Journal of Intelligent and Fuzzy Systems, 14, 2, 5972, 2003.

[35] Arrais-Castro A., Varela M.L.R., Putnik G.D., Ribeiro R.A., Dargam F., Collaborative negotiation platform for networked organizations using dynamic multi-criteria decision model, International Journal of Decision Support System Technology, 7, 1, 1-14, 2014.

[36] Jassbi J.J., Ribeiro R.A., Varela M.L.R., Dynamic MCDM with future knowledge for supplier selection, Journal of Decision Systems, Knowledge-Based Decision Systems, 23, 3, 232-248, 2014.

[37] Vieira G.G., Varela L.R., Ribeiro R.A., A knowledge based system for supporting sustainable industrial management in a clothes manufacturing company based on a data fusion model, S. Liu et al. [Eds.], Decision Support Systems VI - Addressing Sustainability and Societal Challenges, Lecture Notes in Business Information Processing (LNBIP) 250, pp. 113-126, 2016.

[38] Schau E.M., Fet A.M., Assessing the ecological soundness of organic and conventional agriculture by means of life cycle assessment (LCA) - a case study of leek production, British Food Journal, 111, 10, 1028-1061, 2009. 
[39] Kengpol A., Boonkanit P., The development and application of a decision support methodology for product eco-design: a study of engineering firms in Thailand, International Journal of Management, 27, 1, 185-202, 2010.

[40] Dan Z., Yu X., Yin X., Bai Y., Song D., Duan N., An analysis of the original driving forces behind the promotion of compulsory cleaner production assessment in key enterprises of China, Journal of Cleaner Production, 4, 8-14, 2013.

[41] Principi P., Fioretti R., A comparative life cycle assessment of luminaires for general lighting for the office - compact fluorescent (CFL) vs Light Emitting Diode (LED) - a case study, Journal of Cleaner Production, 83, 96-107, 2014.

[42] Kluczek A., Assessment of the eco-efficiency of manufacturing processes based on MFA-LCAMFCA methods, Environmental Engineering and Management Journal, in press.

[43] Feng S.C., Joung C.B., An overview of a proposed measurement infrastructure for sustainable manufacturing, Proceedings of the 7th Global Conference on Sustainable Manufacturing, IIT Madras, Chennai, India, 2009.

[44] Goyal P., Rahman Z., Corporate sustainability performance assessment: an analytical hierarchy process approach, International Journal of Intercultural. Information Management, 4, 1-14, 2014.

[45] Bertoni M., Hallstedt S., Ola I., A model-based approach for sustainability and value assessment in the aerospace value chain, Advances in Mechanical Engineering, 7, 6, 1-19, 2015.

[46] Agarwal P., Sahai M., Mishra V., Bag M., Singh $\mathrm{V}$., A review of multi-criteria decision making techniques for supplier evaluation and selection, International Journal of Industrial Engineering Computations, 2, 801-810, 2011.

[47] Coyle G., The Analytic Hierarchy Process (AHP), Practical Strategy: Structured Tools and Techniques, Pearson Education, Glasgow, 2004.

[48] Sudarsan R., Sriram, R.D., Narayanan, A., Sarkar P., Lee J.-H., Lyons K.W., Kemmerer S.J., Sustainable manufacturing: metrics, standards, and infrastructure - workshop summary, Automation Science and Engineering (CASE), 2010 IEEE Conference on 21-24 Aug. 2010.

[49] Cziner K., Tuomaala M., Hurme M., Multi-criteria decision making in process integration, Journal of Cleaner Production, 13, 475-483, 2005.

[50] Honkasalo N., Rodhe H., Dalhammar C., Environmental permitting as a driver for eco-efficiency in the dairy sector: a closer look at the IPPC Direc- tive, Journal of Cleaner Production, 13, 1049-1060, 2005.

[51] Goodson R.E., Read a Plant Fast, Harvard Business Review, 80, 5, 105-113, 2002.

[52] Lehmar K., Facility logistics. Approaches and Solutions to the next generations challenges, Auerbach Publications, Boca Raton, 2008.

[53] Quintero R.R., Genty A., Vieitez E.R., Wolf O., Development of green public procurement criteria for water-based heaters, Technical Report and Draft Criteria Proposal, JRC Science and Policy Reports, 2014.

[54] Bai S-W., Zhang J-S., Wang Z., Methodology for evaluating cleaner production in the stone processing industry: case study of a Shandong stone processing firm, Journal of Cleaner Production, 102, 461-476, 2015.

[55] Jayal A.D., Badurdeen F., Dillon Jr O.W., Jawahir I.S., Sustainable manufacturing: Modeling and optimization challenges at the product, process and system levels, CIRP Journal of Manufacturing Science and Technology, 2, 144-152, 2010.

[56] Ulewicz R., Jelonek D., Mazur M., Implementation of logic flow in planning and production control, Management and Production Engineering Review, 7, 1, 89-94, 2016.

[57] Widyaningrum D., Masruroh N.A., Development of the sea fishery supply chain performance measurement system: a case study, International Journal Supply Chain Management, 1, 3, 2012.

[58] Gupta V., Supply Chain management - a three dimensional framework, Journal of Management Research, 5, 4, 76-97, 2013.

[59] Ho W., Xu X., Dey P.K., Multi-criteria decision making approaches for supplier evaluation and selection: A literature review, European Journal of Operational Research, 202, 16-24, 2010.

[60] Morgan J.M., Liker J.K., The Toyota product development system: integrating people, process, and technology, Productivity Press, New York, USA, 2006.

[61] Brugha C.M., Structure of multi-criteria decisionmaking, Journal of Operational Research Society, 55, 11, 1156-1168, 2004.

[62] Triantaphyllou E., Using the analytic hierarchy process for decision making in engineering applications: some challenges, International Journal of Industrial Engineering: Applications and Practice, 2, 1, 35-44, 1995.

[63] Oyatoye E.O., Okpokpo G.U., Adekoya G.A., An application of analytic hierarchy process (AHP) to 
investment portfolio selection in the banking sector of the Nigerian capital market, Journal of Economics and International Finance, 2, 12, 321-335, 2010 .

[64] Dahlgaard J.J., Kristensen, K., Kanji G.K., Fundamentals of total quality management, process analysis and improvement, Taylor\&Francis, London New York, 2002.
[65] Kluczek A., Gladysz B., Analytical Hierarchy Process/Technique for Order Preference by Similarity to Ideal Solution-based approach to the generation of environmental improvement options for painting process. Results from an industrial case study, Journal of Cleaner Production, 101, 360-367, 2015. 